\title{
A avaliação da educação superior diante de uma colonialidade do saber e do poder: a participação política discente
}

\author{
Douglas Aparecido de Campos
}

Resumo: Este artigo é o resultado de investigação em pós-doutorado ${ }^{1}$ que analisou e discutiu a participação política dos estudantes nos espaços democráticos de duas universidades públicas: no Brasil e Portugal. Sob o enfoque do colonialismo, ainda presente na atualidade, e da colonialidade do poder e do saber nas interações acadêmicas desenvolvemos as discussões, tendo como fundamentação o referencial teórico de Boaventura de Sousa Santos. Investigamos os fatores que provocam essa despolitização dentro da comunidade acadêmica, principalmente, os que afetam e criam culturalmente essa omissão do corpo discente nas deliberações próprias dos setores da universidade, instituição esta, que deveria garantir o direito de participação política em todas as suas instâncias. Temos como pontos principais: primeiro, o de que democracia e participação são entes distintos, mas, convergentes; segundo, que a participação exige pelo menos três condições: o caráter cultural, o caráter político e caráter epistemológico. Neste contexto desenvolveremos no primeiro momento a democracia como princípio e a estrutura organizacional como fundamento das universidades públicas, a partir das mudanças implementadas nos últimos anos nas universidades brasileiras com a Reestruturação e Expansão das Universidades Federais - REUNI; no segundo momento, o colonialismo, ainda, presente nas universidades, bem como a descaracterização de sua estrutura (fundamento), a partir das relações de poder entre suas bases, principalmente, no que diz respeito às relações entre corpo docente e discente. Os instrumentos metodológicos principais foram questionários e entrevistas. Os resultados demonstraram que em ambas as instituições não há formação política orientada ao corpo discente. Os alunos entram e saem da universidade despolitizados.

Palavras-chave: Participação política. Educação superior.Avaliação.

\section{The evaluation of higher education before a coloniality of the power and the knowledge: the student's political participation}

Abstract: This paper ${ }^{2}$ is the result of the pos doctorate research that analyzed and discussed the student's political participation in the democratic spaces of two public universities: in Brazil and Portugal. We developed the discussion under the Boaventura de Sousa Santos's theoretic referential focusing in the Colonialism approach still present today and the Coloniality of the Power and the knowledge in the academics interactions. We investigated the factors that cause the depoliticization inside of the academic community, especially those that affect and culturally create in the student's team the omission in the deliberations of the university sector. Thisinstitutionshouldguaranteetheright of student'spoliticalparticipation in all of itsinstances. Wehave as mainpoints: first, thedemocracy and participation are distinctsentities, butconvergents and, in second place, theparticipationneed to threeconditions: the cultural character, politicalcharacter and epistemologicalcharacter. In thiscontextwewilldevelop in thefirstmoment: thedemocracy as principle and theorganizationalstructure as foundation to thepublicuniversities, as fromthechangesimplemented in thelastyears in thebrazilianuniversitieswiththerestructuring and theexpansion of the federal universities - (REUNI); in thesecondmoment, thecolonialismstillpresent in theuniversities and themischaracterization of thepublic federal universitiesstructure (foundation) as fromthepowerrelationsexisting in its bases, mainly, about to therelationshipbetweentheprofessor and studentsteams. Themainmethodologicinstrumentswerequestionnaires and the interviews. Theresultsshowedthat in bothinstitutionshave no politicalformationsorientedforthestudent'steam. Thestudentsget in and getoutdepoliticized.

Key words: Political participation. Higher Education. Evaluation.

1 Pesquisa financiada pela Fundação de Amparo à Pesquisa do Estado de São Paulo, FAPESP, processo número 2013/22612-8, orientada pelo prof. Dr. Boaventura de Sousa Santos, CES, UC, Portugal.

2 Research financed by FAPESP (Foundation San Paul State Research Support), process number 2013/22612-8, oriented by prof. PHD Boaventura de Sousa Santos, CES, UC, Portugal. 


\section{A democracia e os espaços democráticos dentro das Universidades}

Nossa discussão inicial aborda a problemática de que a universidade com seus estatutos e normatizações que estabelecem o direito ao acesso do corpo discente aos espaços de representatividade política nas suas instâncias decisórias, ainda que sejam necessários, não garantem a participação em vários dos processos pedagógicos e didáticos que ocorrem ao longo da vida do corpo discente dentre eles, por exemplo, a inclusão de disciplina que desenvolva sua formação política. Há um espaço vazio entre o direito e a garantia desse direito. Essas duas instâncias básicas que definem e modelam a democracia mundial se encontram separadas por uma falsa sensação de autossuficiência embutida no direito, com o conformismo de que a garantia se cumprirá apenas com a publicação das leis que definem e constituem corpo e voz a esse direito. A mensagem embutida no art. $3^{\circ}$ da Lei de Introdução às normas do Direito Brasileiro de que ninguém pode alegar o desconhecimento da lei para agir em desconformidade com a legislação não garante a ação legal de todos (BRASIL, 1942). Falta-nos os mecanismos de liâme entre as duas instituições (direito e garantia) que pode e deve estar no ato educacional embutido na Educação Básica do cidadão. A formação política do cidadão como ato educacional e que engloba a sua participação política no cotidiano deve estar presente em todos os momentos de formação do indivíduo (inicial e continuada). Esse ato formativo presente nos currículos e nas práticas pedagógicas dos professores seria o suficiente para a eficácia devida ao princípio da "publicidade" que rege o direito e sua garantia. $\mathrm{O}$ descumprimento ou o não querer se amoldar às normas, ainda possível, a nosso ver, ficaria adstrito as normas do livre arbítrio que, também, não deixa de ser um fato extremamente político (GRAMSCI, 1978, p.15), mas, neste contexto, um fato subjetivo, consciente, sabido e querido pelo autor, portanto, um não querer político. Dentro desse sistema falho as Universidades Públicas, como última etapa do processo educacional básico, deveriam rever seus objetivos de formação inicial e criar mecanismos de garantias de direitos publicizados, inclusive, em seus estatutos, decretos, regimentos, portarias e outras normatizações para a participação efetiva dos discentes em suas deliberações, de modo a habilitá-los e instrumentalizá-los politicamente para a sua atuação futura na sociedade.

Conforme art. 207 da Constituição Federal Brasileira(BRASIL, 1988) a universidade brasileira atualmente é composta por três pilares que a define e sustenta: o Ensino, a Pesquisa e a Extensão. Esses entes estruturantes 
definem, dão forma, solidificam e fundamentam a universidade, caracterizando-a desde sempre como entidade a serviço do bem comum. Qualquer transformação ou reforma universitária terá essa base como sustentação. Sua construção, dentro destes fundamentos, está atrelada a 03 classes distintas de sujeitos que efetivamente constroem e dão vida à Universidade. Em quaisquer de suas ações, as quais são efetivamente desenvolvidas: pelo corpo docente, pelo corpo discente e pelos técnicos administrativos. Suas atribuições, ainda que epistemologicamente sejam específicas e distintas umas das outras, perpassam por momentos de mesclagem, de conexões e de interações próprias da autonomia de cada Universidade e da cultura ou da metodologia que cada qual segue e que produz ou não, uma identidade democrática. O apogeu democrático de sustentação dessas bases ocorre justamente na participação efetiva das três classes na política interna por meio dos órgãos colegiados superiores e outras instâncias de participação democrática, tais como: comissões, diretórios e demais conselhos universitários. Mas, a democracia interna interage dialeticamente com a democracia externa e esta, a externa, tem passado por períodos dinâmicos de atribulações e conflitos que interferem diretamente na democracia interna, a partir de interposição de políticas públicas de fundamento extremamente econômico em detrimento do fundamento educacional. Nessa condição de "adesão" e de "subordinação" desestabiliza-se o princípio democrático que pressupõe dentre tantos outros o princípio da autonomia, o qual sempre foi cláusula pétrea na criação da universidade pública. Essas condições impostas traz a desestabilização do princípio democrático pela interposição de realidades desconexas das realidades ou cotidiano das universidades brasileiras que seguem parâmetros e orientações inadequadas porque são próprias de outras realidades.

Este fato político por razões econômicas desencadeia o continuísmo colonialista e deixa marcas profundas na universidade pública. A universalidade que se dicotomizou entre o público e o privado e desencadeou toda a cotidianidade vigente, ainda hoje, nos campi universitários tornou a universidade um espaço hierarquizado, não público, portanto elitizado, terceirizado e excludente. Em termos democráticos e de uma forma aristotélica podemos dizer que houve uma degeneração democrática na universidade que demagogicamente passou a ser desenvolvida e instituída de forma falsa, totalmente disforme daquilo que se entende por universal e pública. No âmbito do ensino manteve-se mais acirrada a hierarquização entre corpo docente e discente, talvez um resquício da didática tradicional. Na pesquisa, a 
elitização se tornou evidente. Para poucos e, centrada nas áreas tecnológicas, em detrimento das ciências humanas elevam os professores pesquisadores a uma posição diferenciada dentro da academia e, ainda, todo o aparato de sustentação para a consecução de seus objetivos científicos são elevados em termos econômicos, criando disparidades enormes em relação ao ensino e à extensão. Esta última, a extensão, torna-se totalmente desqualificada e marginalizada com pouquíssima adesão, diminuindo excessivamente a interação devida da universidade com a comunidade externa.

No âmbito administrativo mantem-se estruturas ditas democráticas de participação pública com assentos garantidos por lei a toda a comunidade universitária, mas, que de maneira demagógica, também, seguem os mesmos parâmetros hierarquizados e dicotomizados presentes nos três pilares: Ensino, Pesquisa e Extensão. É visível, por exemplo, uma procura maior para a permanência em posições de deliberações afetas à pesquisa devido ao seu "status" e condições de financiamento incentivadas inclusive pelos órgãos e agências financiadoras do governo e de grupos particulares. Ao contrário, essas posições deliberativas da extensão e do ensino é de menor procura e interesse por parte da comunidade acadêmica. Os assentos ainda que preenchidos em procedimento eleitoral ficam vazios nas reuniões deliberativas, essas, muitas vezes, estendidas em seu tempo para atingir o quórum e na maioria das vezes sem a presença do corpo discente. Outros importantes espaços democráticos como os pertinentes aos assuntos comunitários e estudantis, administrativos, departamentais, centro acadêmico, reuniões de centro, de coordenações, etc., são ainda mais esvaziados e desconsiderados.

Essa hierarquização provoca outro fenômeno que recai diretamente na conceituação de universalização. O corpo docente estimulado pelas políticas colonizadoras de apoio desmedido somente à pesquisa passa por um processo atual de perda de identidade em sua carreira porque começam a investir e a migrar totalmente seus afazeres para apenas o campo da pesquisa e em conhecimentos direcionados por quem os financia. As aulas e os projetos de extensão já não são mais considerados como próprio de sua profissão. Há uma decadência profissional instalada na academia que reflete diretamente nos outros dois pilares. A característica básica da universidade e que a faz assim ser é, justamente, porque essa instituição faz Ensino, Pesquisa e Extensão. Quando ela passa a atuar apenas na pesquisa se degenera da mesma forma em que degenerada está a democracia em seu interior. O ensino e a extensão passam a categorias descartáveis. A qualidade fica empobrecida, as aulas e práticas pedagógicas estagnadas, e os programas e projetos de 
extensão, na mesma medida, sem significado e sentido para a comunidade externa. Aliás, há uma mesma lógica instalada atualmente na extensão. $\mathrm{O}$ governo em uma tentativa de otimizar a extensão passa a financiar projetos e programas de extensão com foco em determinados eixos ou temáticas que julga importante, portanto, da mesma forma direcionado. O corpo docente se motiva por conta do financiamento e participa de programas e projetos de extensão com os temas condicionados por outrem. A universidade nunca foi tão direcionada como o é hoje. O poder de criação e de liberdade acadêmica para atuar em assuntos que a academia crê importante está hoje controlado por essa política colonizadora instalada nos financiamentos e fomentos em todos os níveis.

Essa situação agrava-se a partir do movimento de reestruturação das universidades implantado pelo governo federal conhecido como REUNI. Um movimento, sem dúvida, necessário e ambicioso que definitivamente atingiu o princípio do ser Público, porque efetivamente abriu a universidade para todos. Possibilitou o acesso à universidade às classes sociais denominadas, antigamente, de populares, mas o fez sem a devida preparação, tanto estrutural (meios físicos, arquitetônicos, logísticos, etc.), como formativa e de recursos humanos (formação continuada docente, formação continuada de técnicos administrativos, contratações, etc.). A universidade dobrou ou triplicou de tamanho em todos os aspectos sem a capacidade para tal. Entretanto, os espaços democráticos, permaneceram os mesmos, no mesmo formato. Essas estruturas foram e são implementadas aos poucos à medida que não se consegue atuar coerentemente e com qualidade, assim, nasce, por exemplo, o grupo gestor das ações afirmativas em decorrência do acesso de populações indígenas, de afro descendentes, de refugiados; da criação de cursos para a população do movimento dos sem terra; da criação de novas pró-reitorias, novos conselhos e outros tantos espaços que, infelizmente, surgem a partir da provocação de uma situação e não a partir de uma discussão democrática, planejada, criada com tempo e qualidade necessários. Essa opressão se faz sentir nos espaços democráticos em seu interior com o emudecimento do corpo docente, discente e dos técnicos administrativo que também operam os sistemas administrativos. As ideias ficam adstritas à possibilidade imposta e controlada pela intervenção direta daqueles que as financiam e determinam. A liberdade de criação agora determinada e contida contém da mesma maneira a liberdade de participação, de deliberação e de debate, já que não se pode ir além daquilo que é determinado sob o peso de se perder os "incentivos". Como diz Fukuyama (1992, p.117) "[...] o avanço 
científico depende não só de liberdade para investigação, mas também de uma sociedade e sistema político em que haja uma completa abertura para o debate livre e a participação."

Acirrou-se a não participação política nesses espaços juntamente com a falta de formação para atuação coerente, lógica e adequada, devido, principalmente, à diversidade populacional que adentrou à universidade e que se traduz por meio de culturas, saberes, conhecimentos, costumes, religiões, gênero, escolha sexual, etnias, etc.; e, também dentro de uma estrutura organizacional e política engessada, ainda, com as feições do passado. Como afirma Santos (2012, p. 431), uma universidade que vive ainda das consequências de vícios passados que se concretizam em:

Inércia e endogamia por detrás da aversão à inovação; autoritarismo institucional disfarçado de autoridade académica; nepotismo disfarçado de mérito; elitismo disfarçado de excelência; controlo político disfarçado de participação democrática; neofeudalismo disfarçado de autonomia departamental ou facultaria; temor da avaliação disfarçado de liberdade académica; baixa produção científica disfarçada de resistência heroica a termos de referencia estúpidos e a comentários ignorantes de referees.

A participação política pressupõe mais que um simples ato de fala ou de expressões pantomímicas. A participação subentende um estar presente de forma imanente que pressupõe uma peculiaridade do sujeito em relação ao ato de estar naquele lugar e espaço, ou seja, o querer estar naquele momento tem significado social pertinente para o seu ser e, mais que isso, tem um sentido que lhe é próprio e individual e que tem por finalidade o bem estar de uma coletividade, da qual ele pertença ou não. Portanto, a participação deve ter um fundo teleológico que está presente na formação do sujeito ao longo da vida e no seu desenvolvimento cultural, a partir desse processo. Isso significa que os valores culturais em sua formação são os agentes protagonizadores do desenvolvimento de sua atitude de participação nos eventos democráticos.

Para além da pré-disposição correta de agir coerentemente com os valores culturais é preciso a conexão com a condição política de abertura de possibilidades de participação e de respeito a esse envolvimento do sujeito descendente de comunidades culturais diferenciadas desde que, como alertaSantos (2010b, p.375) sejam dadas "[...] iguais condições para as diferentes soluções institucionais multiculturais se desenvolverem segundo a sua lógica própria". 
Então, é pressuposta uma condição acima de tudo epistemológica que encare a participação política e a transformação a partir da garantia da presença e do reconhecimento dos saberes que advém dessa multiculturalidade dos participantes. Assim, as condições políticas, culturais e epistemológicas são os pilares de sustentação de uma participação efetiva e eficaz.

A universidade está nesse processo de transição em que não cabe mais a postura de uma "democracia representativa" em seu interior. Essa forma de governo ou de "governança" já não lhe cabe porque a realidade multicultural proveniente de sua abertura para as classes populares "obriga-a" a uma transformação que tenha como princípio a participação efetiva e de qualidade. Analogamente aSantos(2010b), ecompreendendo a universidade como um microcosmo, entendemos ser esse o momento de uma universidade que tenha como objetivo a coordenação de estratégias e ações para um enaltecimento das instituições democráticas em seu interior balizada nas concepções de mundo dessa nova comunidade diversa e intelectualmente ativa. Santos(2010b, p.372) diz que "As tarefas de coordenação são antes de tudo de coordenação de interesses divergentes e até contraditórios". Santos(2010b), fala assim de uma "democracia redistributiva" que segundo ele não pode ficar limitada à democracia representativa por que essa já não tem mais a competência para proceder a distribuição das ações, porque, metodologicamente, está defasada para a nova realidade. No nosso caso, a defasagem é proveniente de uma nova cultura, de uma nova política e de uma nova epistemologia no interior da universidade que provoca a mudança e a urgência de um novo modelo que perpassa, justamente, pela democracia participativa que complementa, dialeticamente, a democracia representativa. Diz o autor:

É que nas condições da nova constelação política a democracia representativa perdeu as parcas virtualidades distributivas que alguma vez teve. Por isso, nestas novas condições a democracia redistributiva tem de ser democracia participativa e a participação democrática tem de incidir tanto na actuação estatal de coordenação como na actuação dos agentes privados, empresas, organizações não governamentais, movimentos sociais cujos interesses e desempenho o Estado coordena (SANTOS, 2010b, p.372).

Essa orientação vai ao encontro do que aqui vimos discutindo, ou seja, a necessidade da reformulação dos espaços de participação democrática dentro da universidade pela própria universidade, com a postura de uma 
coordenadora que distribui as ações a serem efetivadas e deliberadas e, ainda, dentro dos parâmetros: cultural, político e epistemológico.

Essa nova estrutura que nasce da dialética entre a democracia representativa e a participativa não pode ser diferente de um espaço que se concebe dialógico, que tenha a segurança de uma participação confiável e idônea, ou seja, que a participação seja instrumentalizada para um agir coerente e eficaz. A democracia não é silenciosa, se faz dentro de barulho. A própria existência humana, segundo Freire (1979) é repleta de ruído, não se concebe muda.

A democratização da Universidade e de outras instâncias e entidades em diversas áreas continua sendo um movimento atual no Brasil e no mundo. Basta-nos relembrar dos movimentos sociais que organizaram vários protestos no país por meio das redes sociais conclamando os cidadãos, cujos atores principais, em sua maioria, foi de estudantes. Com o objetivo de reivindicar melhores tarifas de transportes públicos surgiram também várias outras

reivindicações com faixas e cartazes sobre a Educação, a Segurança, a Saúde, dentre outros. A nosso ver, um verdadeiro paradoxo já que essa atitude de participação política não ocorre como deveria ocorrer dentro da academia, como vimos discutindo. Nossa impressão é a de que essa juventude sem a formação política entra nas manifestações políticas sem saberem o que querem, ou seja, sabem o que de momento não lhes interessa, mas, não sabem efetivamente dizer, demonstrar e justificar o desenvolvimento e a criação de um outro paradigma que transforme e ultrapasse o estado ao qual eles insurgem. Fukuyama (1992, p. 330) em contexto histórico análogo explica esse fenômeno pelo o que ele designa de "tédio" que aliado a uma prosperidade pode ser o fator desencadeador desse processo social de participação com uma certa irracionalidade. A esse fenômeno de reivindicação e de manifestos Santos (2010a), denomina de cosmopolitismo subalterno:

Consiste num vasto conjunto de redes, iniciativas, organizações e movimentos que lutam contra a exclusão económica, social, política e cultural gerada pela mais recente incarnação do capitalismo global, conhecido como globalização neoliberal. Atendendo a que a exclusão social é sempre produto de relações de poder desiguais, estas iniciativas, movimentos e lutas são animados por um ethosredistributivo no sentido mais amplo da expressão, o qual implica a redistribuição de recursos materiais, sociais, políticos, culturais e simbólicos e, como tal, se baseia, simultaneamente, no princípio da igualdade e no princípio do reconhecimento da diferença (SANTOS, 2010a, p.42). 
Esse cosmopolitismo subalterno está inserido no sentido de universalização que pressupõe uma educação pública de qualidade apoiada nos três pilares sobreditos (Ensino, Pesquisa e Extensão) e que nos dias atuais é uma forte demanda social, amparada por políticas públicas, pela sociedade de maneira uniforme, geral e pela plena convicção de se garantir os direitos previstos e elencados nas leis.

Esse movimento de transformação ou de requerimento social ocorre a partir das vivencias e experiências sociais passadas dentro do colonialismo e torna-se ação efetiva a partir da habilitação e instrumentalização ocorrida no âmbito social, ainda que de maneira oculta e não intencional e por um autodidatismo social. São vivências ocorridas no desenvolvimento das políticas oligarquizantes, das decisões monopolizadas, desmandos, aviltamentos e demais séries de improbidades, humilhações, discriminações e opressões sofridas pela sociedade ao longo do tempo. As ações privaticionistas e mercantilistas inseridas também no âmbito educacional transformaram os pilares de sustentação da universalidade. Tiraram sua dinamicidade, desconectaramse, dicotomizaram-se e, atrelados aos movimentos burocráticos seguiram os mesmos mecanismos meritocráticos de competição e de exclusão. A universidade descaracterizada ou como diria ao longo de sua obra,Santos (1997) em "[...] crise institucional, de legitimidade e de hegemonia" agora particularizada, restrita, específica, personalizada, enfim, elitizada deixou sua vocação de res pública. A universidade fechada em si sob o fundamento de uma "desconfiada" autonomia segue com esses parâmetros ao longo de sua existência como não poderia deixar de ser. Os movimentos posteriores, de abertura, de desconexão com a metodologia colonialista e de recuperação da Universalidade e da vocação da res pública encontraram esse quadro de coisas que ficou arraigado culturalmente no âmago social.

É dentro desse resumido contexto que necessitamos visualizar a universidade pública de hoje para fomentar sua real transformação e reconstruir sua universalidade. Assim, não nos é estranho ainda hoje, em dias "póscolonialistas" uma disfarçada ditadura empresarial ou financeira dentro de uma propalada e desconfiada autonomia universitária que fecha os olhos para a mercantilização das pesquisas acadêmicas, que acabam sustentando laboratórios de pesquisas, equipamentos, bolsas, a infra-estrutura, a política institucional, os usos e costumes na comunidade acadêmica, os procedimentos e técnicas de gestão e de administração e, até mesmo, o modus operandi dos conselhos superiores das universidades, por fim, ditando os rumos nacionais e porque não internacionais da sociedade de modo geral. 
Infelizmente, essa mediocridade vem se alastrando por completo dentro da universidade e afeta atualmente as três classes: docente, discente e técnicos administrativos, portanto afeta, a base de sustentabilidade da universidade que se apoia efetivamente, como já vimos, numa identidade democrática criada a partir da coesão desses três entes que formam a universidade. Como bem explica Santos (2004b, p. 77): “A funcionalização da universidade ao serviço do capital exige a proletarização de docente e pesquisadores, a qual não pode ocorrer enquanto os mecanismos de democracia interna estiverem activos, pois são eles que sustentam a liberdade acadêmica que barra a passagem à proletarização".

Os mecanismos de democracia externa em interação dialética com os mecanismos de democracia interna estão esvaziados. A partir disso ocorre, também, o esvaziamento e a descaracterização dos órgãos colegiados, os centros acadêmicos, os conselhos e comissões e outros espaços coletivos de deliberações e de participação política. Estes deixam de ser espaços legítimos de participação política e se tornam espaços de deliberações técnicas e administrativas. Esse fenômeno descaracterizante dos mecanismos democráticos internos é característica da tensão existente entre a democracia interna e externa, ou seja, externamente não se concebe mais a universidade isolada do bem comum, não é mais cabível uma autonomia universitária que faz apologia à desconexão com a realidade social. Em tempos idos a universidade ditava seu próprio desenvolvimento o que Santos(2010a,b) chama de "auto-regulação" e que sempre era em favor daquilo que ela a universidade "achava" de seu interesse em detrimento do que a sociedade precisava efetivamente. Portanto, a continuação desse paradigma em tempos totalmente diversos como o da atualidade deixa a universidade sem legitimidade para a sua existência. Sua erudição já não é mais o fundamento para o desenvolvimento de suas atividades em prol da elite porque essa "alta cultura" (SANTOS, 1997) já não é mais a única classe a estar no interior da universidade. Hoje há segundo Santos (2004b, p.75) um "[...] apelo à democracia externa" proveniente do cosmopolitismo subalterno em que se reivindica, em linhas gerais, uma certa cumplicidade da universidade em relação à sociedade.

Essa tendência, a nosso ver, tem como pano de fundo a abertura da universidadeàs ditas classes populares; à diversidade transformadora em seu interior; às exigências de reformas estruturais por conta dessa nova demanda; à um paradigma baseado nas novas tecnologias de informação e comunicação - TICs e ao emergente cosmopolitismo subalterno fundamen- 
tado em movimentos sociais que reivindicam responsabilidades sociais à universidade a partir dessa nova realidade. Esse contexto é nomeado por Santos(2004b, p.76) de "pluriversitário".

Deste modo é que se segue com um certo desmonte dos mecanismos da democracia interna porque como produto dessa tensão entre a democracia interna e externa segue também, de modo ambíguo, segundo Santos(2004b, p.75) um apelo privaticionista por “[...] grupos sociais diferentes e com interesses contraditórios”. Esses grupos colocam a falta de acesso à universidade como o mote para a privatização. Com isso a auto-regulação deixa de existir, ou seja, a universidade passa a se desenvolver de conformidade com as orientações e vontades oriundas da privatização. Esta, por sua vez, independe dos mecanismos democráticos da democracia interna, aliás, estes seguem como inoportunos para o movimento privaticionista. A proletarização das classes que atuam na universidade e o desmonte dos espaços e mecanismos democráticos é uma sequência lógica para a desestabilização democrática interna. Paradoxalmente há uma preocupação pelo acesso que certamente invoca um pensamento democrático, mas, os meios como se pretender resolver são demagógicos. Da mesma forma a legitimidade universitária sai do contexto da "alta cultura" (SANTOS, 1997), mas, passa para o contexto do mercado consumidor e industrial, ou seja, em nome de interesses puramente econômicos e quantitativistas concebe-se e legitima-se uma nova universidade.

\section{O colonialismo e a colonialidade na Universidade}

As possibilidades de participação política de todos na academia ainda esbarram em muitas influências e maneirismos solidificados da época colonial que acabam por tornar o processo de reeducação um tanto moroso, ainda que objetivo, ideal, refletido, e condizente com a nossa realidade. Chamamos aqui de colonialismo disfarçado, Santos(2010b) de "governança neoliberal" e Quijano(2010, p.73) de colonialidade que está presente nas relações de poder e de saber. Explica:[...]"Sustenta-se na imposição de uma classificação racial/étnica da população do mundo como pedra angular do referido padrão de poder e opera em cada um dos planos, meios e dimensões, materiais e subjectivo, da existência social quotidiana e da escala societal".

É o caso específico da universidade pública que apesar das imposições porque passou e, ao nosso ver, ainda passa, também resguarda conhecimentos e saberes próprios de sua realidade como forma de uma resistência oculta às 
imposições e ingerências sofridas ao longo de tantos anos por essas políticas colonizadoras. A sua própria estrutura ou aquilo que chamamos de "fundamento", ou seja, os três pilares que a constitui, é uma forma organizacional modelada e desenvolvida ao longo desses anos que sofreu e sofre ataques da colonialidade para uma descaracterização. Segundo Santos (2010a, p. 13):

[...] o colonialismo, para além de todas as dominações porque é conhecido, foi também uma dominação epistemológica, uma relação extremamente desigual de saber-poder que conduziusupressão de muitas formas de saber próprias dos povos e nações colonizados, relegando muitos outros saberes para um espaço de subalternidade.

Entendemos que está embutido nesse processo desenvolvimental saberes próprios da realidade brasileira que resistiram à metodologia de subalternidade do colonialismo e que possibilitou um diálogo mínimo entre ciência e saberes externos à universidade. Do mesmo pensamento corroboraSantos (2010a, p.44-45) que propõe este novo olhar para o sul de forma a aprender com ele e sua epistemologia.

A universidade colonizada e sua ciência devem ser examinadas tendo em conta essa particularidade dialética apesar das origens de sua constituição. Santos (2004a, p. 3) explica:

A la universidad le compete organizar ese compromisso, congregando a los ciudadanos y a los universitários en autênticas comunidades interpretativas que superen las usuales interaciones en las cuales los ciudadanos son siempre obligados a renunciar a su propia interpretación de la realidade social.

Com o acesso das camadas populacionais à universidade mudou de aparência. Já não mais se reconhece a universidade do passado a não ser pela sua estrutura organizacional ainda presa ao passado resistindo de maneira equivocada a essa nova e riquíssima diversidade cultural no seu interior. Santos (2010a) chama a atenção para a importância dessa diversidade. Essa metodologia colonizadora arraigada ainda às práticas pedagógicas e administrativas na universidade é ainda um dos fatores do continuísmo dessa herança colonial que insiste em desconsiderar os saberes da diversidade em prol de uma pretensa modernidade e "erudição". Meneses(2010, p. 75) complementa:

Esta negação da diversidade das formas de perceber e explicar o mundo é um elemento constitutivo e constante do colonialismo. No 
entanto, e muito embora a dimensão política da intervenção colonial tenha sido amplamente criticada, o ónus da monocultura colonial epistémica ainda é actualmente aceite como um símbolo de desenvolvimento e modernidade. (MENESES, 2010, p.205)

Freire(2011, p.75) explica a dificuldade para se proceder a transformação depois de um grande tempo sob o domínio da colonialidade: "Por vezes, os colonizadores são expulsos, mas permanecem culturalmente, porque foram assimilados pela mente das pessoas que ali ficaram. Essa terrível presença persegue o processo revolucionário e, em certos casos, impede o movimento de libertação".

Santos(2010a, p. 31) confirma a presença atual do colonialismo:

O meu argumento é que esta realidade é tão verdadeira hoje como era no período colonial. O pensamento moderno ocidental continua a operar mediante linhas abissais que dividem o mundo humano do sub-humano, de tal forma que princípios de humanidade não são postos em causa por práticas desumanas. As colónias representam um modelo de exclusão radical que permanece actualmente no pensamento e práticas modernas ocidentais tal como aconteceu no ciclo colonial. Hoje, como então, a criação e ao mesmo tempo a negação do outro lado da linha fazem parte integrante de princípios e práticas hegemónicos.

A universidade de hoje extremamente aberta, diversa, heterogênea e multicultural tem um novo padrão, ou como diria (Santos,2010a) tem uma nova epistemologia. Fazendo comparações e analogias, é como se a população ou os povos que pertencia antigamente à linha de lá do hemisfério, portanto, pertencente ao sul e ao âmbito dos países colonizados, tivessem e tiveram a oportunidade de ascender à linha de cá do hemisfério, portanto, pertencentes ao norte e ao âmbito dos colonizadores. Comparações a parte, o fato político é o de que essa diversidade de saberes não pode e nem deve ser desconsiderada como se faz dentro da colonialidade. Pressupomos dentro desse contexto, uma universidade que atua com a "ecologia de saberes" e que vá mais além,Como o próprio Santos (2010b) nos informa: quea universidade atente não somente para a diversidade de saberes, mas, principalmente, para a diversidade epistemológica dentro dessa nova universidade. Neste sentido, a formação inicial e continuada com bases na participação política a partir dessa diversidade e para um atuar conectado com a dinâmica social é fator preponderante nessa nova universidade. Também é do mesmo parecer 
Meneses(2010, p.231), sobre a prática acadêmica pós-colonial que deverá seguir com uma "[...] formacão das identidades e das subjectividades, bem como do relacionamento entre os saberes e as práticas políticas".

A universidade desestabilizada por conta de uma nova realidade, imersa na diversidade de saberes e experiências humanas em seu interior e sem saber como proceder dentro desse novo contexto, socorre-se no endurecimento de suas antigas barreiras. A colonialidade do poder e do saber neste sentido ficam enaltecidas ao extremo e, paradoxalmente, ao mesmo extremo, é enaltecida a ignorância da academia ao desconsiderar e se afastar mais ainda dos saberes dessa diversidade. A isto Santos(2010a, p. 500) chama de "ingenuidade" e explica que "[...] o conhecimento erudito ou académico tem uma relação ingénua com o conhecimento que considera ingénuo".

Essa nova realidade tem como princípio a vivencia do ser humano na diversidade, no pluralismo, na heterogeneidade e nas diferenças. São padrões antigos e novos ao mesmo tempo que hoje são discutidos e estão em processo de compreensão. Não sabemos, ainda, como prosseguir nessa diversidade. Estamos no momento dialético de reflexão porque compreendemos que os padrões anteriores já não são mais suficientes para explicar a dinâmica social atual ou que, pelo menos, ele pode não ser o único. $\mathrm{O}$ autor ao dizer sobre a dinamicidade social diz que "estamos de novo perplexos, perdemos a confiança epistemológica" (SANTOS, 2010c, p.8). A participação política a partir dessa compreensão será certamente o fator de auto-regulação e de emancipação da universidade porque os direitos e garantias estarão presentes na ação coerente e segura de cada sujeito que faz a universidade e de acordo comSantos(2010b, p.160), "[...] em igualdade de circunstâncias preferindo a forma de conhecimento que garanta a maior participação dos grupos sociais envolvidos na concepção, execução, controle e fruição da intervenção".

\section{Metodologia/Análise}

Apoiamos a investigação nas três categorias de análise que efetivamente formam a complexidade da participação política dentro da democracia. Há momentos em que se torna possível demonstrar claramente cada uma delas em separado, mas, em outros, devido à abrangência de cada uma delas, umas sobrepõem-se às outras. Por meio de questionários e entrevistas aplicados aos alunos de ambas universidades foi possível analisar, discutir e identificar os fatores Culturais, Políticos e Epistemológicos nas respostas coletadas que nos levaram à afirmação da quase inexistência de participação política do 
corpo discente nos espaços democráticos das universidades. As entrevistas foram aplicadas junto aos estudantes que claramente são ativos participantes nos espaços democráticos. Os questionários foram aplicados via email, por meio da ferramenta limesurvey e alguns de forma pessoal em sala de aula.

Os questionários foram enviados a 7145 alunos. Desse total obtivemos 247 acessos sendo que 62 estudantes acessaram e não completaram os questionários. Tivemos 185 respostas válidas que equivale a 2,58\% de participação. Do total de 185 respostas obtivemos 107 do gênero feminino (57,83\%); 78 do gênero masculino (42,16\%). Os questionários revelam que 150 estudantes do total de 185 respostas não participam de nenhum espaço político e democrático o que equivale a uma porcentagem de $81,08 \%$. Nas questões afetas ao gênero, os dados demonstram uma ligeira maior participação feminina nos espaços políticos. Do total de 185 respostas temos 20 participantes do sexo feminino $10,81 \%$ contra 15 do gênero masculino $(8,10 \%)$ o que perfaz $18,91 \%$ do total. Com referência às áreas de conhecimento temos uma grande participação política nos espaços democráticos pertencentes aos alunos das ciências humanas. Do total de 185 respostas temos 157 estudantes das ciências humanas (84,86\%), 25 estudantes das ciências exatas $(13,51 \%)$ e 03 da pós-graduação 1,62\%. A partir do total de 35 participações políticas nos espaços democráticos dentro da universidade sobressaem 29 estudantes que pertencem às mais variadas áreas de conhecimento das ciências humanas $(82,85 \%), 03$ estudantes das ciências exatas $(8,57 \%)$ e 03 estudantes da pós-graduação $8,57 \%$.

Sob a análise da categoria Cultura verificamos que os alunos engajados ou que estão mais presentes em ações de cunho político nas universidades são justamente aqueles que de uma forma ou de outra tiveram ao longo de suas vidas uma formação voltada para a participação em ações familiares, escolares e sociais. Esse atributo de cidadania tem em sua gênese: a família como instituição importantíssima na educação; a escola como locus desencadeador de solidariedade, de visão do bem comum, de criação de valores éticos e morais, o debate, e tantos outros porque possibilita o convívio em comunidade, despertaram necessidades outras e criam oportunidades de vivencias democráticas quando estabelecem em seu planejamento a criação de espaços políticos, tais como: grêmios estudantis, conselhos, as associações acadêmicas e outras atividades recreativas e educacionais como as gincanas, etc.; que possibilitam atuar em e para a comunidade em que o sujeito está sendo formado (FUKUYAMA, 1992). Da mesma forma demonstra a importância dessas instituições na vida dos cidadãos que são 
atos, vivências e experiências formativas que conduzirão no futuro as ações e posicionamentos individuais e coletivos ao caminho da democracia.

$\mathrm{Na}$ era moderna, a cidadania é exercida através das chamadas "instituições intermédias" - partidos políticos, empresas privadas, sindicatos, associações cívicas, organizações profissionais, igrejas, associações de pais, conselhos escolares, tertúlias, etc. É através deste tipo de associações cívicas que as pessoas dão o melhor de si, ultrapassando as suas preocupações egoístas (FUKUYAMA, 1992, p.322-323).

Sob a análise da categoria Política verificamos que a vivencia desde cedo nessa cotidianidade cria expectativas e orienta o indivíduo em busca de mais participação e envolvimento nas instâncias mais complexas, como por exemplo, universidade. A decepção da maioria dos estudantes que têm esse histórico de vida é a de não poder prosseguir o aprofundamento dessa formação cidadã no espaço universitário porque efetivamente a universidade não o faz. Buscam essa formação em outras entidades, por exemplo, sindicatos e outros agentes políticos privados que proporcionam de forma regressista uma formação política enviesada a esses indivíduos cooptados, com os interesses puramente privaticionistas, individuais e que acabam desvirtuando a democracia interna nas universidades com atuação desses indivíduos formados de maneira errônea. Não podemos aqui deixar de compreender que os processos de ensino e de aprendizagens podem ser utilizados tanto para o bem como para o mal. Como diz Santos(2003, p.131), "[...] experiência de vida são uma faca de dois gumes, sendo que algumas delas podem ser mobilizadas de forma progressista e outras em direção regressiva". A importância da formação direcionada por docentes reside justamente em realizá-la pelo caminho progressista. Quando a academia omite uma formação política direcionada com a intencionalidade progressista corre o risco de receber discentes orientados na contramão desse objetivo, ou seja, para o lado regressista. Essa colonialidade está também presente nas instituições representativas do corpo discente pela mesma ligação ou conectividade com partidos políticos ou outras organizações políticas estruturadas que se aproveitam do nível de desinformação ou de ingenuidade das representações discentes e que acabam por colonizá-las e descaracterizá-las com o mesmo processo de cooptação.

Sob a análise da categoria "Epistemologia" verificamos o "acaso" como forma de participação; a falta de tempo do corpo discente por conta de um grande número de afazeres provenientes de um currículo inchado; o des- 
conhecimento do que significa poder e dever participar de ações políticas; o desconhecimento do que significa não "fiscalizar" e interagir com as representações de classe eleitas e, o mais importante, o desconhecimento dos direitos e garantias e a crença "cega" de que a garantia do direito reside apenas no ato de uma publicação normativa. Essa despolitização descaracteriza as instituições democráticas no interior da universidade infantilizando-as e rebaixando-as a meros espaços de reivindicação festiva. A infantilidade contamina os indivíduos que passam a ser meros agentes promocionais desses eventos.

\section{Conclusões}

A Universidade não forma o sujeito politicamente. $\mathrm{O}$ estudante entra e sai da universidade despolitizado. Os currículos estão demasiadamente grandes em relação ao tempo de permanência do estudante na instituição, o que provoca o desestímulo e a falta de participação política. Os conteúdos curriculares precisam ser revistos para a inclusão de disciplinas que tenham como objetivo a formação política. Essa transformação curricular permitirá a criação de metodologias que permitam a vivência do corpo discente não somente nos espaços democráticos, mas, de forma geral em todos os espaços acadêmicos, hoje subutilizados em sua maioria. Há um engessamento da criatividade individual e dos processos de ensino e de aprendizagem, por conta de uma competição ainda desmedida no ensino que orienta os atores, corpo docente e discente, a uma egocentricidade acadêmica. Essa egocentricidade estabelece uma superposição hierárquica que deve existir sem dúvida, mas ao menos, como afirma Santos(2004b, p.2) com hierarquias que "[...] devem ser estabelecidas em um contexto argumentativo" e dentro dos princípios da igualdade e do respeito pela diferença. Segue-se a mesma lógica para a transformação interna com bases na participação de toda a comunidade universitária. A transformação/formação de comunidades interpretativas no seu interior necessita ser entendida a partir dessa complexidade negativa criada pela governança neoliberal que utiliza mecanismos desativadores dos conceitos ou propostas emancipatórias e transformadoras. Esses mecanismos são os causadores da despolitização no interior da universidade e são também os deflagradores da desconexão das condições de participação das comunidades interpretativas porque efetivamente separam a condição cultural da condição política e destas à condição epistemológica. Como diz Santos (2010a) a partir desse movimento a sociedade passa a viver das 
“consequências" porque a partir dessas é que se desenvolvem alternativas de prosseguimento que, em sua maioria, segue a lógica neoliberal da exclusão e o continuísmo da desconexão. Da mesma forma Campos e Mello, (2015, p.252) chamam a atenção para o desenvolvimento de políticas públicas pre-factumou "prospectivas" que previnam o acontecimento dos fenômenos e factos indesejáveis e prejudiciais, ao invés de políticas públicas post factumem analogia à causa e consequência. $\operatorname{Santos}(2010$ b, p. 120-122) novamente, também, aponta caminho similar com o uso da combinação das "sociologias das ausências e das emergências" em que as primeiras se baseiam nas experiências sociais que já existem post factum e as segundas nas experiências sociais possíveis pre-factum. Prossegue (SANTOS, 2002, p. 30) dizendo que a "[...] ciência moderna desenvolveu uma enorme capacidade de agir, mas não desenvolveu uma correspondente capacidade de prever.'Voltamos, então, ao cerne da questão que está contido na transformação social a partir da participação social. Conforme (SANTOS, 2010b, p.406) "[...] não há benefício sem participação; e não há participação sem benefício". Os mecanismos neoliberais descaracterizam por completo a participação e ao fazê-lo descaracterizam a transformação. Esse jogo estratégico situado também no interior da universidade, a nosso ver, é a causa da despolitização e da falta de participação da comunidade nos espaços democráticos. Santos(2010b, p. 406-407) explica essa complexidade:

Tal equação decorre das seguintes premissas: o direito a determinar o benefício cabe a quem participa; a condição para uma tal autodeterminação é a autodeterminação da participação. A matriz da governação lida com esta equação de uma forma complexa. Ela aceita a equação na condição de substituir a participação autodeterminada por uma participação baseada num princípio de seleção segundo o qual apenas alguns actores, interesses ou vozes são admitidos a participar. A participação pode ser autónoma, mas não os critérios de escolha dos participantes. Pode haver benefícios para os que são admitidos, mas sempre à custa da invisibilização dos preteridos. A equação é, assim, desenraizada e instrumentalizada.

Vamos além, essa metodologia da governança neoliberal provoca um fenômeno no mínimo curioso e, não menos trágico, dentro dos grupos que se dizem democráticos dentro de um processo, também, dito democrático, porque, formalmente, é realizado por meio de critérios de elegibilidade, de representação, de deliberação, de apresentação de propostas, como é o caso das várias eleições que ocorrem para o preenchimento de diversas vagas nos 
órgãos de representação e até na consulta à comunidade para as reitorias. A equação aqui decorre das mesmas premissas explicadas por Santos(2010b), e desencadeia o sentimento de pertença dos grupos de que aquilo, pelo qual digladiam, é exclusividade, propriedade deles. É um "nacionalismo" em menor escala. Como bem diz Fukuyama(1992, p. 266), "A dignidade que os nacionalistas querem ver reconhecida não é, porém a dignidade humana universal, mas a do grupo". Um grupo não deixa o poder porque justifica que o grupo oponente vai desestabilizar a democracia instalada pelo grupo que permanece no poder. $\mathrm{O}$ fenômeno paradoxal é o de que a permanência do grupo que se diz democrático é realizada e concretizada pelo uso das mesmas premissas que descaracterizam a democracia. Então, no mesmo sentido deSantos(2010b) precisamos questionar que condições políticas são essas hoje presentes na universidade que em nome de uma "democracia" utiliza princípios de seleção tão antidemocráticos; que condições culturais devemos enaltecer e considerar advindas da diversidade se, culturalmente, a universidade, ainda, utiliza as premissas da governança neoliberal e, finalmente, que saberes ou que condições epistemológicas a universidade vai considerar se, epistemologicamente, utiliza de conhecimentos tão aviltantes da cidadania em seus processos internos.

\section{Referências}

BRASIL.Lei n. 4.657, de 04 de setembro de 1942 - Lei de Introdução às Normas do Direito Brasileiro. 1942. Disponível em: $<$ http://www.planalto. gov.br/ccivil_03/decreto-lei/Del4657compilado.htm>. Acesso em: 14 jan. 2015.

\section{BRASIL.Constituição da República Federativa Brasileira de 1988.}

1.988. Disponível em:<http://www.planalto.gov.br/ccivil_03/constituicao/ constituicaocompilado.htm>.Acesso em: 14 jan. 2015.

CAMPOS, Douglas; MELLO, Maria Aparecida.Student Access and Retention in Brazilian Higher Education: Reflections and Commentary on Public Federal Universities. In: STEAD, V. Peter Lang (org.).International perspectivesonhighereducationadmissionpolicy. New York: Peter Lang, 2015 . 
FREIRE, Paulo. Pedagogia do oprimido.7. ed.Rio de Janeiro: Paz e Terra, 1979.

FREIRE, Paulo. In: MACEDO, D. A democracia imposta: diálogos com Noam Chomsky e Paulo Freire. Portugal: EdiçõesPedago, 2011.

FUKUYAMA, Francis. The end of history and the last man. New York: a division of Maxwell Macmillan, 1992.

GRAMSCI, A. Concepção dialética da história. 3.ed.São Paulo:

Civilização Brasileira, 1978.

MENESES, M.P. Corpos de violência, linguagens de resistência: as complexas teias de conhecimentos no Moçambique contemporâneo. In: SANTOS, B. de S.; MENESES, M. P. (Orgs.). Epistemologias do Sul. São Paulo: Cortez, 2010.

SANTOS, B. de S.Pela mão de Alice: o social e o político na pósmodernidade. 3.ed. São Paulo: Cortez, 1997.

SANTOS, B. de S.A crítica da razão indolente: contra o desperdício da experiência.Para um novo senso comum. A ciência, o direito e a política na transição paradigmática. 2. ed. Porto: Edições Afrontamento, 2002.v. 1.

SANTOS, B. de S.Democratizar a democracia: os caminhos da democracia participativa.Porto: Edições Afrontamento, 2003.

SANTOS, B. de S.Tesis para una Universidad pautada pela ciencia postmoderna. Educación Superior: Cifras e Hechos,Espanha,v. 3, n. 18, 2004a.

SANTOS, B. de S.A Universidade no Século XXI: Para uma reforma democrática e emancipatória da Universidade. 3. ed. São Paulo: Cortez, 2004b.

SANTOS, B. de S.Para além do pensamento abissal: das linhas globais a uma ecologia de saberes. In: SANTOS, B. de S.; MENESES, M. P. (Orgs.). Epistemologias do Sul. São Paulo: Cortez, 2010a.

SANTOS, B. de S.A gramatica do tempo: para uma nova cultura política. 3.ed. São Paulo: Cortez, 2010b. 
SANTOS, B. de S.Um discurso sobre as ciências. 16. ed.Porto: Edições Afrontamento, 2010c.

SANTOS, B. de S.A cor do tempo quando foge: crônicas 2001 - 2011. Coimbra: Edições Almedina, 2012.v.2.

QUIJANO, A.Colonialidade do poder e classificação social. In: SANTOS, B. de S.; MENESES, M. P. (Orgs.). Epistemologias do Sul. São Paulo: Cortez, 2010 .

Douglas Aparecido de Campos- Universidade Federal de São Carlos São Carlos | SP | Brasil. Contato: dcampos@ufscar.br

Artigo recebido em 17 de agosto de 2015 e aprovado em 15 de maio de 2016. 
